\title{
Determining the Influence of Oral Health Infotainment Module on Behavior and Oral Hygiene of 6-year-old School- children and their Mothers in Davangere City
}

\author{
Ipshita Potlia ${ }^{1}$, PG Naveen Kumar ${ }^{2}$, Manumanthu V Ramesh ${ }^{3}$, Himanshu Chauhan $^{4}$, Arun R Nair ${ }^{5}$, Alok KR Singh
}

\begin{abstract}
Aim and background: Dental plaque and calculus are common in school-aged children worldwide causing unsatisfactory oral health. This stage is a critical time to establish attitudes, beliefs, and shape an individual's health-related behavior. Moreover, parental oral health knowledge and attitudes are known to influence their child's oral health and hygiene.

Materials and methods: A cross-sectional study with a two-stage intervention trial involving a sample of 6-year-olds from two schools in Davangere city was done. Children were randomly allocated into three intervention groups by lottery method. Data included plaque index (PI) modified for 6-year-old children at baseline, 30th day, and at 60th day. Children and their mothers were requested to fill a self-administered questionnaire. The statistical analysis used ANOVA followed by Tukey's post hoc test and measures ANOVA. $p \leq 0.05$ was considered statistically significant.

Results: There was a significant reduction in the PI modified in 6-year-olds within and among the three groups at the end of 60 days ( $p=0.001)$. Maximum reduction was seen in group II followed by group III and thereafter group I in both the age-groups.

Conclusion: The study shows that at 60 days, the oral health infotainment module involving parental support was able to achieve appreciable improvement in the child's oral health and hygiene and inculcate a better attitude toward oral self-care.

Keywords: Infotainment module, Mothers' knowledge, Oral health promotion, Oral hygiene.

International Journal of Clinical Pediatric Dentistry (2021): 10.5005/jp-journals-10005-2031
\end{abstract}

\section{INTRODUCTION}

Oral health plays a pivotal role in the maintenance of overall health and it meaningfully impacts the value of life. ${ }^{1}$ Dental caries and periodontal diseases cause irreversible damage, pain, anxiety, despair, low self-confidence, and lost school/working hours of children and adults. ${ }^{2}$

These can be viewed as behavioral diseases, preventable by simple oral hygiene practices. ${ }^{3}$

During school years, children are receptive to accepting and maintaining positive health behaviors, the earlier the habits are established, the longer their impacts last. ${ }^{4}$

Parental familiarity and understanding of oral health certainly play an influential role. ${ }^{5}$ Their level of education is the significant determinant of oral health in children worldwide. ${ }^{6}$ Whereas mother's edification proves to be a better prognosticator for health disparities amid children. ${ }^{7}$ This is because mothers are known to assume the role of primary caregivers in the early formative years of their children. The association between the dental well-being of mothers and that of their progenies has been stressed by various researchers. ${ }^{8}$

Healthiness is achieved by preventive, behavioral, educational, empowerment, and social change. Prevention emphases in reduction of disease levels, where health expert is proficient and the patients are beneficiaries of preventive care, behavioral amendment aims to inspire individuals to be accountable for their well-being and accept a healthier régime to their lifestyle. This tactic is founded upon the concept that the information will transform behavior. ${ }^{9}$

Educational change helps individuals and communities, acquire the eye to identify their own apprehensions, priorities and to develop skills to address these issues. Social change highlights
${ }^{1}$ Department of Public Health Dentistry, Saraswati Dental College, Lucknow, Uttar Pradesh, India

2,5 Department of Public Health Dentistry, Faculty of Dental Sciences, Banaras Hindu University, Varanasi, Uttar Pradesh, India

${ }^{3}$ Department of Public Health Dentistry, Vishnu Dental College, Bhimavaram, Andhra Pradesh, India

${ }^{4,6}$ Department of Oral and Maxillofacial Surgery, Saraswati Dental College, Lucknow, Uttar Pradesh, India

Corresponding Author: Ipshita Potlia, Department of Public Health Dentistry, Saraswati Dental College, Lucknow, Uttar Pradesh, India, Phone: +91 8318679725, e-mail: dripshitapotlia@gmail.com

How to cite this article: Potlia I, Naveen Kumar PG, Ramesh MV, et al. Determining the Influence of Oral Health Infotainment Module on Behavior and Oral Hygiene of 6-year-old Schoolchildren and their Mothers in Davangere City. Int J Clin Pediatr Dent 2021;14(5):633-639. Source of support: Nil

Conflict of interest: None

the importance of socioeconomic and environmental aspects in determining health. ${ }^{9}$

These changes bring about a positive effect at individual, interpersonal, and community levels, it is, therefore, preferable to combine all the health promotion models under an umbrella of a preventive intervention to gain maximum impact on the masses. ${ }^{10}$

One of the well-developed models currently being used for the purpose is the (Predisposing Reinforcing Enabling Constructs in Educational/Environmental Diagnosis Evaluation) 
PRECEDE-PROCEED Model (Policy Regulatory Organizational Constructs Educational Environmental). Combining the essentials of the individual, interpersonal, and community levels. ${ }^{11}$ The model clearly states that behavioral change is a voluntary activity and offers methodical planning, distribution, and appraisal of health promotion programs. ${ }^{10}$

Educative resources which present striking and appropriate focus to respective age-group could kindle better oral health behavior. ${ }^{12}$ The most common source of entertainment for children of this particular age-group is known to be animated movies or cartoons. Animated movies focused on promoting healthy oral hygiene habits were selected as a means of providing oral health education for children. Increase in consumption of processed food, aerated drinks, in-between meal snaking, and increased sugar intake in the form of chocolates, etc., the oral health of children is affected adversely. It is hence the need of the hour to bring a change in their eating and oral hygiene habits. With this knowledge in the background, the present study was planned to assess the effect of the Oral Health Infotainment Module on Behavior and Oral Hygiene of 6-year-old schoolchildren and their mothers in Davangere City.

\section{Materials and Methods}

This was a cross-sectional study with a two-stage intervention trial involving 6-year-old children in Davangere city. The data included calculation of PI modified for 6-year-old children at baseline, 30th day, and at 60 th day. Children and their mothers were requested to fill a self-administered questionnaire at the same time. From each of the two schools, selected randomly from the north and south zones of Davangere city, all of the 6-year-old schoolchildren who fulfilled the inclusion and exclusion criteria and whose parents gave consent for participation were included in the study. The children were randomly allocated into three intervention groups using the lottery method.

A pilot study was conducted to check the validity of the study and to assess the feasibility of students and their mothers to understand and answer the questionnaire. The sample size was determined based on the pilot study, which was found to be 160 , but considering dropouts it was rounded off to 200 .

\section{Classroom-based Intervention}

Classroom-based intervention was common to all of the intervention groups and was applied in a class by means of learning tools in form of various animated movies (infotainment module) for children, guiding children to brush twice daily with fluoride toothpaste. Two such interventions were conducted in a month, lasting for 20-30 minutes. Following this, the investigator explained the teachings of the movie at a pace that the children were able to appreciate and grasp. The three intervention groups in the study are as follows:

Group I-Classroom-based intervention for students

Group II-Classroom-based intervention for students and orientation-based intervention for mothers

Intervention to mothers was provided by giving oral health education in form of an interactive orientation session. This session was organized in the form of a parent-teacher meeting where the parents were explained the importance of good oral health, methods of maintaining good oral hygiene and the concept of daily twice brushing of teeth using fluoridated toothpaste, etc., role modeling of parents in good oral health behaviors were also highlighted.

Group III-Classroom-based intervention for students and SMS-based intervention for mothers

In this group, health education was given to the mothers on phone by means of a text message (SMS) sent twice a month.

\section{Questionnaires}

Questionnaires were created by referring to previous literature on oral healthcare behaviors, information, and attitude ${ }^{13}$ to evaluate the child's and mother's knowledge and attitudes toward their oral wellbeing. Reliability and validity of these questionnaires were assessed and Cronbach's alpha values attained were 0.84 and 0.88 for the two separate questionnaires.

\section{Clinical Examination}

Clinical examination was performed following American Dental Association (ADA) Type III examination in the school during school time, before lunch.

\section{Data Collection}

Questionnaires were filled in class under supervision before the clinical examination. All of them were given a cover letter and mother's questionnaire, to be filled and returned to school in a week, all of the mothers responded. Response for every question varied, but was no $<86 \%$. Only seven children were excluded from the clinical examination, as they were undergoing orthodontic treatment and one child's mother was a dentist.

\section{Statistical Analysis}

Data compiled in Microsoft Excel sheet were analyzed using the Statistical Package for Social Sciences (SPSS) version 22.0. Since the data were continuous, quantitative type and normally distributed, parametric tests were used for analysis. Descriptive analysis was done for the questionnaire given to the mothers and children separately.

\section{Results}

Table 1: Distribution of study subjects according to age and gender

\begin{tabular}{|c|c|c|c|c|}
\hline \multirow{3}{*}{$\begin{array}{l}\text { Study } \\
\text { groups }\end{array}$} & \multirow[b]{3}{*}{ Intervention } & \multicolumn{2}{|c|}{$\begin{array}{l}\text { Number of } \\
\text { subjects }\end{array}$} & \multirow[b]{3}{*}{ Total } \\
\hline & & Male & Female & \\
\hline & & 6 years & 6 years & \\
\hline Group I & $\begin{array}{l}\text { Classroom-based interven- } \\
\text { tion for students }\end{array}$ & 40 & 26 & 66 \\
\hline Group II & $\begin{array}{l}\text { Classroom-based inter- } \\
\text { vention for students and } \\
\text { orientation-based interven- } \\
\text { tion for mothers }\end{array}$ & 33 & 36 & 69 \\
\hline Group III & $\begin{array}{l}\text { Classroom-based inter- } \\
\text { vention for students and } \\
\text { SMS-based intervention for } \\
\text { mothers }\end{array}$ & 32 & 34 & 66 \\
\hline $\begin{array}{l}\text { Total } \\
\text { subjects }\end{array}$ & & 105 & 96 & 201 \\
\hline
\end{tabular}




\section{Discussion}

According to $\mathrm{WHO}$, at the age of 5-6 years most of the primary teeth are present in the oral cavity providing better assessment of oral hygiene for the primary dentition. It has also been stated that in children younger than 6 years of age it is recommended that the brushing be performed by an adult until the child has developed sufficient manual dexterity and cognitive skills to perform their toothbrushing independently. ${ }^{14}$ Therefore, child's oral hygiene is also influenced by their mother's attitudes toward this practice. As

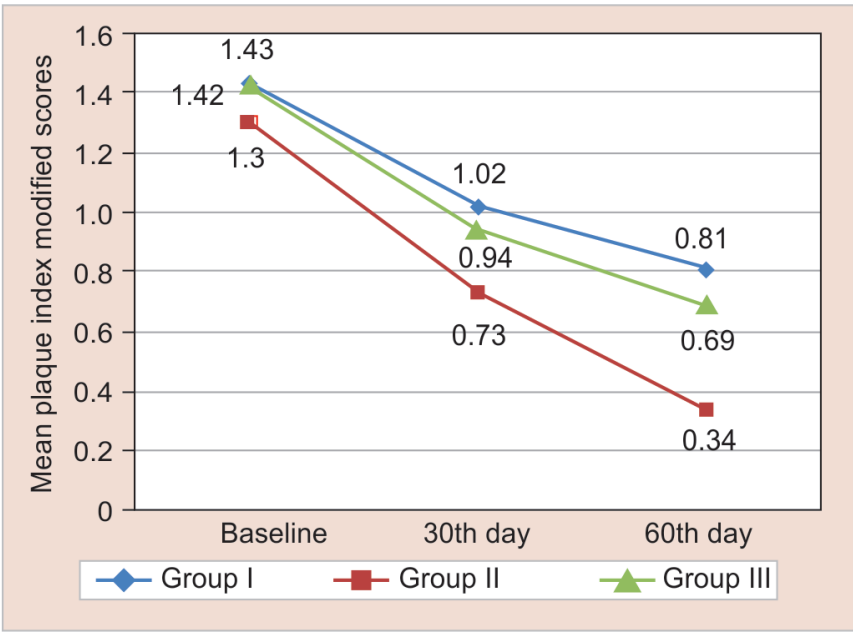

Fig. 1: Mean plaque index modified scores for 6-year-old children this is one of the index age-groups by WHO, hence this age-group of subjects was considered for the present study.

Promotion of oral health at school level is received well, can be effective, economical, and advantageous to the entire community. ${ }^{1}$ Schools can provide an important network and channel to the local community. Similarly, through the children, health awareness can be passed on to other members of the family.

The reason why these programs have been futile to further children's oral health behavior is due to the paucity of suitable, instructive dental educational resources. Attractive and stimulating infotainment modules specific to each age-group could inspire better oral health behavior. ${ }^{12}$

Infotainment means broadcasting material which is intended both to inform and entertain. The most common source of entertainment for children of this particular age-group is animated movies or cartoons. Hence, animated movies which focused on promoting healthy oral hygiene habits were selected as to provide oral health education.

Barring school the other most important place where children are seen to learn and spend most of their time is their home with family. It is considered as an influential social milieu to encourage physical and emotional well-being, to influence concepts about health and health behaviors. ${ }^{15}$ Even when it comes to family, children are known to spend most of the time with mothers at home, which is the reason why they play a key role in instilling good general health, oral health, and habits. Especially in a society like ours, where mothers play a substantial role toward nurturing their children. This formed the reason for selecting mother child pairs in the present study.

Table 2: Inter- and intra-group comparison of mean plaque index modified scores at various time intervals for 6-year-old children

\begin{tabular}{|c|c|c|c|c|c|c|c|}
\hline \multirow[b]{2}{*}{ Time interval } & & \multicolumn{3}{|c|}{ Groups } & \multicolumn{2}{|c|}{ One-way ANOVA } & \multirow[b]{2}{*}{ Tukey's post hoc } \\
\hline & & I & II & III & Fvalue & $p$ value & \\
\hline Mean baseline (1) & & $1.43 \pm 0.44$ & $1.30 \pm 0.46$ & $1.42 \pm 0.39$ & 1.469 & 0.233 (NS) & \\
\hline Mean 30th day (2) & & $1.02 \pm 0.55$ & $0.73 \pm 0.39$ & $0.94 \pm 0.45$ & 5.060 & $0.008(\mathrm{HS})$ & $\mathrm{II} \leq \mathrm{III} \simeq 1$ \\
\hline Mean 60th day (3) & & $0.81 \pm 0.44$ & $0.34 \pm 0.20$ & $0.69 \pm 0.30$ & 26.103 & $0.000(\mathrm{HS})$ & $\mathrm{II} \leq \mathrm{III} \simeq \mathrm{I}$ \\
\hline Repeated measures & $F$ value & 29.443 & 154.318 & 162.177 & & & \\
\hline ANOVA & $p$ value & $0.001(\mathrm{HS})$ & $0.001(\mathrm{HS})$ & $0.001(\mathrm{HS})$ & & & \\
\hline Pairwise comparison & & $3<2<1$ & $3<2<1$ & $3<2<1$ & & & \\
\hline
\end{tabular}

NS, non significant $(p>0.05)$; S, significant $(p \leq 0.05) ; \mathrm{HS}$, highly significant $(p \leq 0.01)$

Group I-Classroom-based intervention for students, group II-Classroom-based intervention for students and orientation-based intervention for mothers, group III-Classroom-based intervention for students and SMS-based intervention for mothers

Table 3: Inter- and intra-group comparison of mean scores of standardized questionnaire at various time intervals for 6-year-old children

\begin{tabular}{|c|c|c|c|c|c|c|c|}
\hline \multirow[b]{2}{*}{ Time interval } & & \multicolumn{3}{|c|}{ Groups } & \multicolumn{2}{|c|}{ One-way ANOVA } & \multirow[b]{2}{*}{ Tukey's post hoc } \\
\hline & & 1 & II & III & Fvalue & $p$ value & \\
\hline Mean baseline (1) & & $10.70 \pm 2.35$ & $10.60 \pm 1.77$ & $11.00 \pm 1.56$ & 0.116 & 0.891 (NS) & \\
\hline Mean 30th day (2) & & $13.00 \pm 2.16$ & $12.10 \pm 1.19$ & $12.60 \pm 2.50$ & 0.493 & 0.616 (NS) & \\
\hline Mean 60th day (3) & & $13.20 \pm 1.22$ & $14.00 \pm 1.49$ & $13.70 \pm 1.88$ & 0.671 & 0.519 (NS) & \\
\hline \multirow{2}{*}{$\begin{array}{l}\text { Repeated measures } \\
\text { ANOVA }\end{array}$} & $F$ value & 11.697 & 10.015 & 18.118 & & & \\
\hline & $p$ value & $0.004(\mathrm{HS})$ & 0.007 (HS) & $0.001(\mathrm{HS})$ & & & \\
\hline Pairwise comparison & & $3>2>1$ & $3>2>1$ & $3>2>1$ & & & \\
\hline
\end{tabular}

$\mathrm{NS}$, non significant $(p>0.05)$; S, significant $(p \leq 0.05)$; HS, highly significant $(p \leq 0.01)$ 


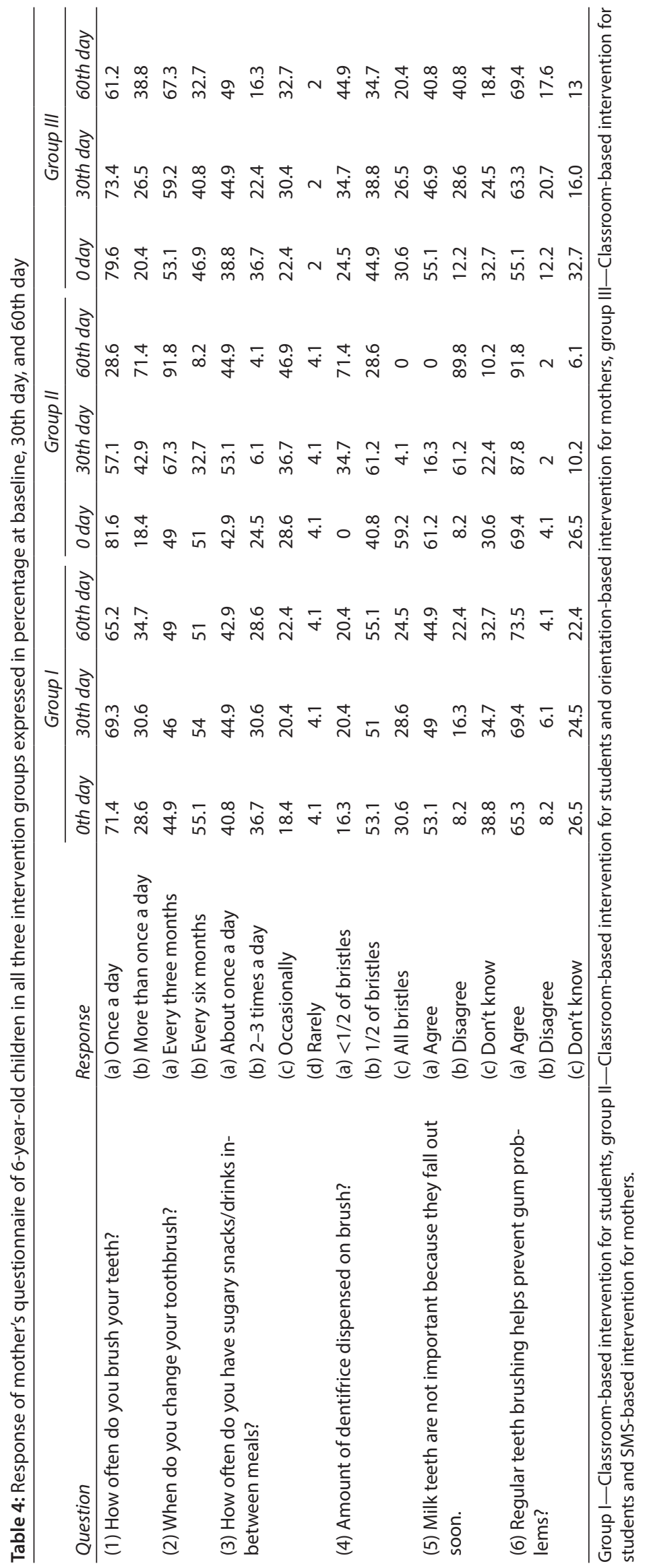


Presence of debris, dental plaque, and calculus are common oral hygiene problems seen in children. These problems if not taken care of or corrected at the initial stages may further lead to gingivitis, halitosis, and dental caries.

\section{Intra-group Comparisons between Baseline, 30th Day, and 60th Day for 6-year-old Children (Tables 1 to 3 and Fig. 1)}

Plaque Index Modified Scores for 6-year-old Children (Table 2)

A linear reduction in plaque index modified scores was seen from baseline to 60 days which was statistically highly significant ( $p<$ 0.001).

These results were similar to a studies done by Tai et al. ${ }^{16}$ in China among 6-7-year-old children and Hartono et al. ${ }^{17}$ in 8-12-yearold children from Indonesia, suggesting that the school-based oral health promotion was an effective way to reduce new caries incidence, improve oral hygiene, and establish positive oral health behavioral practices in the targeted schoolchildren.

For group II, these results were similar to studies done by Mohebbi et al. ${ }^{18}$ and Kowash et al. ${ }^{19}$ which showed significant improvement in plaque values of children and mothers participating in the study, implying oral health education is a valuable tool for promoting oral health behavior in mother child pairs.

The additional orientation based intervention to the mothers of these children, where oral health education was provided could also further improvise the results of the study. As mothers' positive attitude toward oral health are known to be related to children's better dental health ${ }^{20}$ along with their gingival health. ${ }^{21}$

For group III, these results were similar to studies done by Mohebbi et al. ${ }^{18}$ and Finlayson et al. ${ }^{22}$ which showed significant improvement in plaque values of children and mothers participating in the study, highlighting the influence of mothers involvement in their child's oral health behavior and oral hygiene.

The additional SMS-based intervention to the mothers of these children, where messages pertaining to the importance of maintain good oral hygiene and various tips on improving their child's oral health was sent to these mothers. These messages may have acted as constant reminders to them of the importance of oral health which may have influenced their child's oral hygiene.

This was one of the novel studies where a SMS-based intervention was used to provide oral health education to the mothers, which also makes literature search in the aspect of studies using short message service limited to compare with the present study.

\section{Scores for Standardized Questionnaire (Tables 3 to 5)}

A linear increase in the scores was seen from baseline to the end of 60 days was noticed which was statistically highly significant.

These results of the standardized questionnaire were similar to a study conducted by Saied-Moallemi et al. ${ }^{23}$ among 9-yearolds in Tehran, Iran, where a school based oral health intervention significantly improved the knowledge, attitude, and awareness regarding oral health and hygiene which was analyzed by means of a self-administered questionnaire given to the students.

This improvement in the group can be attributed to the oral health education being imparted during the behavior formative age of children. Further improvement could be due to the use of infotainment module which aids in grasping the attention span and engaging them for a longer period of time, as it was easy to understand for children. 


\section{Inter-group Comparisons between Baseline, 30th Day, and 60th Day for 6-year-old Children (Tables 1 to 3 and Fig. 1). \\ Plaque Index Modified Scores (Table 2)}

At the baseline, there was no significant difference in mean PI modified scores between the three groups ensuring between group comparability.

At the end of 30 days, a statistically significant difference was observed in scores between the groups $(p=0.008)$. A significant difference was observed between group II and group I.

At the end of 60 days, again a statistically significant difference was observed in PI modified scores between the groups $(p=0.000)$. Wherein group II had shown the best reduction in PI modified score which was significantly better than group III followed by group I.

\section{Scores for Standardized Questionnaire for 6-year-old Children} (Tables 3 to 5)

At the baseline, there was no significant difference in mean scores between the three groups showing all the participants had similar knowledge.

At the end of 30 and 60 days, again no significant difference was seen among the three groups, however, numerically there was an increase in their scores when compared with baseline, implying that there was an increase in the understanding and knowledge of the children, but the difference was not significant because all the children were educated toward oral health using the infotainment module together in the same auditorium.

In the present study, improvements were seen in all the three groups, however, marked improvements appeared among the children in the intervention groups involving parents, i.e., group II and III, reflecting high involvement of the parents, these results are in similar to a study conducted by Saied-Moallemi et al. ${ }^{23}$ among 9 -year-old schoolchildren in Tehran, Iran. The better results in the parental aid groups could also be attributed to the fact that parents' awareness of the intervention at school led them to give greater responsibility for their children's oral health.

Overall there was an improvement seen in the knowledge and practices of children and mothers in all the three groups. The better results of group II can be explained due to the involvement of the mothers. As mothers were made aware about the importance of good oral hygiene and were educated about the same, their influence on their child's oral self-care increased. This can specifically be seen in improvements in the responses to question no $1,2,4$, and 5, which are typical attitude and practice related behavior which would show magnified improvements only when the children are being monitored at home. ${ }^{24}$

The group III presented with the next best results where mothers were educated about the importance of good oral hygiene by means of a mobile text message. It seems that mothers awareness of the intervention at school have led them to give greater responsibility for their children's oral health. The results were slightly less remarkable when compared to group II, as mothers were not met with in person, highlighting the importance of an orientation based intervention.

Although improvements were seen in group I, owing to the health education imparted to the children by the examiner using the infotainment module, it showed the least improvement which could be due to the formal and authoritative approach which may have prevented the children from having deep and meaningful communication in oral hygiene instruction,

\section{LiMITATIONS}

The long-term effects of the study could not be assessed as the duration of the study was for only 60 days and like in most questionnaire survey participants had an inclination to give socially suitable answers. This might have resulted in a too-optimistic picture of the current situation. To make sure that honest answers were given, mothers were asked similar questions about children's toothbrushing.

\section{Conclusion}

This study shows how school based oral health education programs can be beneficial in improving the overall awareness of not only the parents involved directly but also those who were not directly a part of the study. Hence, parents should be made conscious about the importance of their role in modifying their child's oral health and behavior.

School-based oral health educational programs should be highlighted and must be integral to all primary schools. They form the platform to implement oral health promotion and remain one of the first and the most important secondary socializing agencies for children. The significance of school's to transfer oral health-related knowledge, healthy behavior, and skills to the children should be understood, thus, modifying the existing system to better serve these aims.

\section{Ethical Clearance}

Ethical clearance for the study was obtained from the Institutional Ethical Committee of College of Dental Sciences, Davangere.

\section{References}

1. WHO (World Health Organization, 2003a). WHO Information Series on School Health, Doc 11; Oral Health Promotion Through Schools. Geneva: WHO; 2003.

2. ADA (American Dental Association). Back-to-school checkup; send your child off to school with a healthy mouth. J Am Dent Assoc 2004;135(8):1203. DOI: 10.14219/jada.archive.2004.0380.

3. Schou L, Blinkhorn A, ed. Oral health promotion. Oxford: Oxford University Press; 1993.

4. Addy M, Hunter ML, Kingdon A, et al. An 8-year study of changes in oral hygiene and periodontal health during adolescence. Int J Paediatr Dent 1994;4(2):75-80. DOI: 10.1111/j.1365-263x.1994. tb00108.x.

5. Petersen PE. Oral health behavior of 6-year-old Danish children. Acta Odontol Scand 1992;50(1):57-64. DOI: 10.3109/00016359209012747.

6. Watt RG. Parental knowledge and attitudes to oral health. Br Dent J 2002;193(11):642. DOI: 10.1038/sj.bdj.4801649.

7. Wamani H, Tylleskär T, Åstrøm AN, et al. Mothers' education but not fathers' education, household assets or land ownership is the best predictor of child health inequalities in rural Uganda. Int J Equity Health 2004;3(1):9. DOI: 10.1186/1475-9276-3-9.

8. Mouradian WE, Wehr E, Grall JJ. Disparities in children's oral health and access to dental care. J Am Med Assoc 2000;284(20):2625-2631. DOI: 10.1001/jama.284.20.2625.

9. Daly B, Watt R, Batchelor P, et al. Essential dental public health. Oxford: Oxford University Press; 2002.

10. Linden A, Roberts N. Disease management interventions: what's in the black box? Dis Manage 2004;7(4):275-291. DOI: 10.1089/ dis.2004.7.275.

11. Green LW, Kreuter MW, Deeds SG, et al. Health education planning: a diagnostic approach. Mountain View, CA: Mayfield Publishing; 1980

12. Redmond CA, Hamilton FA, Kay EJ, et al. An investigation into the value and relevance of oral health promotion leaflets for young 
adolescents. Int Dent J 2001;51(3):164-168. DOI: 10.1002/j.1875595x.2001.tb00834.x.

13. Hobdell M, Petersen PE, Clarkson J, et al. Global goals for oral health 2020. Int Dent J 2003;53(5):285-288. DOI: 10.1111/j.1875-595X.2003. tb00761.x.

14. Cascaes AM, Peres KG, Peres MA, et al. Validity of 5-year-old children's oral hygiene pattern referred by mothers. Rev Saude Publica 2011 Aug;45(4):668-675. DOI: 10.1590/s0034-89102011005000033.

15. Moysés ST, Rodrigues CS. Healthy environments: strategies for promotion of children's oral health. In: Sheiham A, Bönecker M, ed. Promoting children's oral health, theory and practice. Brazil: Quintessence Editora Ltda.; 2006. pp. 1-12. , 77-91.

16. Tai BJ, Jiang $H, D u M Q$, et al. Assessing the effectiveness of a school-based oral health promotion programme in Yichang City, China. Community Dent Oral Epidemiol 2009;37(5):391-398. DOI: 10.1111/j.1600-0528.2009.00484.x.

17. Hartono SW, Lambri SE, van Palenstein Helderman WH. Effectiveness of primary school-based oral health education in West Java, Indonesia. Int Dent J 2002;52(3):137-143. DOI: 10.1111/j.1875595x.2002.tb00618.x.

18. Mohebbi SZ, Virtanen JI, Vehkalahti MM. Improvements in the behaviour of mother-child pairs following low-cost oral health education. Oral Health Prev Dent 2014;12(1):13-19. DOI: 10.3290/j. ohpd.a31227.

19. Kowash MB, Pinfield A, Smith J, et al. Effectiveness on oral health of a long term health education programme for mothers with young children. Br Dent J 2000;188(4):201-205. DOI: 10.1038/sj.bdj. 4800431.

20. Szatko F, Wierzbicka M, Dybizbanska E, et al. Oral health of polish three-year-olds and mothers' oral health-related knowledge. Community Dent Health 2004;21(2):175-180.

21. Greene JC, Vermillion JR. The simplified oral hygiene index. J Am Dent Assoc 1964;68(1):7-13. DOI: 10.14219/jada.archive.1964.0034.

22. Finlayson $\mathrm{TL}$, Siefert $\mathrm{K}$, Ismail $\mathrm{Al}$, et al. Reliability and validity of brief measures of oral health-related knowledge, fatalism and self efficacy in mothers of African American children. Pediat Dentis 2005;27(5):422-428.

23. Saied-Moallemi $Z$, Murtomaa $H$, Tehranchi $A$, et al. Oral health behaviour of Iranian mothers and their 9 -year-old children. Oral Health Prev Dent 2007;5(4):263-269.

24. Sjöström $O$, Holst D. Validity of a questionnaire survey: response patterns in different subgroups and the effect of social desirability. Acta Odontol Scand 2002;60(3):136-140. DOI: 10.1080/000163502753740133. 